Instructions for authors, subscriptions and further details:

http://brac.hipatiapress.com

\title{
Esther Ferrer. Espacios Entrelazados
}

Josu Rekalde-Izagirre

1) University of the Basque Country UPV/EHU. (Spain)

Date of publication: October $3^{\text {rd }}, 2018$

Edition period: October 2018 - February 2019

To cite this article: Rekalde_izagirre J. (2018). Esther Ferrer. Espacios entrelazados. Barcelona, Research, Art, Creation, 6(3) 355-359. doi: 10.17583/brac.2018.3521

To link this article: http://dx.doi.org/10.17583/brac.2018.3521

\section{PLEASE SCROLL DOWN FOR ARTICLE}

The terms and conditions of use are related to the Open Journal System and to Creative Commons Attribution License (CC-BY). 
BRAC - Barcelona Research Art Creation. Vol. 6 No. 3, October 2018, pp. 355-359

(Recibido: 29 mayo 2018; Aceptado: 29 junio 2018; Publicado: 3 octubre 2018)

\section{Review}

Título de la Exposición: ESPACIOS ENTRELAZADOS

Artista: Esther Ferrer

Fecha de la Exposición: 16 de marzo hasta el 10 de junio de 2018

Lugar: Museo Guggenheim en Bilbao

\section{Esther Ferrer. Espacios entrelazados}

Dos exposiciones complementarias de la Artista Esther Ferrer nos dan la oportunidad de ver su trabajo en perspectiva. La primera de ellas tuvo lugar a comienzo del presente año en el Palacio de Velázquez en Madrid con el título de "Todas las variaciones son válidas, incluida esta" y estuvo organizada por el Museo Nacional Centro de Arte Reina Sofía. La segunda está teniendo Lugar actualmente en el Museo Guggenheim en Bilbao con el título "Espacios Entrelazados".

Esther Ferrer (Donostia - San Sebastián 1937) es conocida en gran medida por su dimensión performativa, la cual desarrolló durante casi 30 años junto al internacionalmente prestigioso grupo Zaj, del que formó parte de 1967 a 1996. Antes de unirse a Zaj, Esther trabajaba en múltiples formatos artísticos con los que colaboraba con artistas como José Antonio Sistiaga sobre proyectos de innovación pedagógica -basados en parte por las revolucionarias ideas de Jorge Oteiza-, y a los que denominaban "Talleres de Libre Expresión".

Pero lo más interesante de Esther es que en cualquiera de las facetas que despliega -acciones en directo, composiciones sonoras, fotos y dibujos-, utiliza siempre un mismo concepto rítmico, siguiendo las líneas metodológicas marcadas por John Cage, según las cuales el tiempo en el que transcurre la obra es lo único real. En ese tiempo, cada acto, cada silencio o cada sonido, adquieren múltiples sentidos que surgen siempre en el propio espectador, nunca en la subjetivación del artista. La obra de Esther en este sentido permanece fiel al espíritu Fluxus, en donde una vez que estableces las reglas de juego para la configuración de la obra, ésta funciona sola como una máquina. 
En esta recensión sobre la exposición "Espacios entrelazados", me gustaría detenerme en la serie de obras tituladas Proyectos espaciales. Dicha serie está compuesta por once instalaciones inéditas que se corresponden a proyectos en dibujos o maquetas que datan desde 1990 hasta 2018 y que fueron diseñados por la artista mediante estructuras de cartón similares a las maquetas arquitectónicas. A diferencia de los escultores vascos de la anterior generación, Esther rechaza todo expresionismo, incluso subjetivismo, lo que la diferencia radicalmente de, por ejemplo, la obra de Chillida. Así, estando más cercana a los postulados ideológicos oteicianos, materializa sus ideas en pequeños formatos, sin importarle si posteriormente éstos serán trasladados a una escala mayor. Sin embargo, se aleja de dichos postulados en cuanto al respeto del material utlizado, ya que Esther no desocupa el espacio sólido de un acero o de una piedra, si no que marca sutilmente el espacio con la delicadeza de un hilo de coser que sugiere una forma en el vacío. La artista fija los hilos matemáticamente en los distintos planos de la maqueta, midiendo distancias regulares entre los puntos de sujeción de los mismos, a fin de que, al colocarlos, parezcan líneas que atraviesan el espacio siguiendo esquemas geométricos.

Este método de trabajo en el que se aleja de todo lo expresivo, similar al empleado por los músicos John Cage o Tom Jhonson, , es el que hace que la artista someta a la forma a un gran rigor matemático. Con este proceder, Esther Ferrer sitúa las horquillas de sujeción a diferentes intervalos, midiéndolos para que generen distintos ritmos, direcciones y retículas que logran alterar la percepción del espacio y su dimensión temporal. Este proceso le da infinitas variaciones geométricas, (de ahí el título de la muestra de Madrid: "Todas las variaciones son válidas, incluida ésta"), variando el número de hilos o la distancia entre ellos, modifica el planteamiento matemático, eligiendo una de las posibles variaciones de la serie.

Un buen ejemplo en el proceso matemático de Esther es el uso de los números primos como el de la serie de Fibonacci, o el del número pi, o Teoremas como el de Napoleón-, en los que, como dice ella, se encuentra por el camino al igual que si fuesen objetos (Ready Made) duchamptianos.

Como nos decía la propia artista "Necesito un sistema para huir de la subjetividad estética. Un día incluso soñé que nadaba en un mar de números y todos ellos eran números primos". Esto lo podemos comprobar en esta serie "Proyectos Espaciales", en la que el espacio mismo se comporta como la materia prima de la obra. Esther nos invita a caminar por el espacio como lo hace con su cuerpo en las performances, marcando mínimamente el recorrido. Obras cercanas a un concepto arquitectónico donde los elementos mínimos se 
apropian del espacio, dejándolo transparente, consiguiendo que el aire circule entre las marcas.

Imagen 1. Maquetas de dos instalaciones de Esther Ferrer. (Fotografías cedidas y autorizadas por la autora).
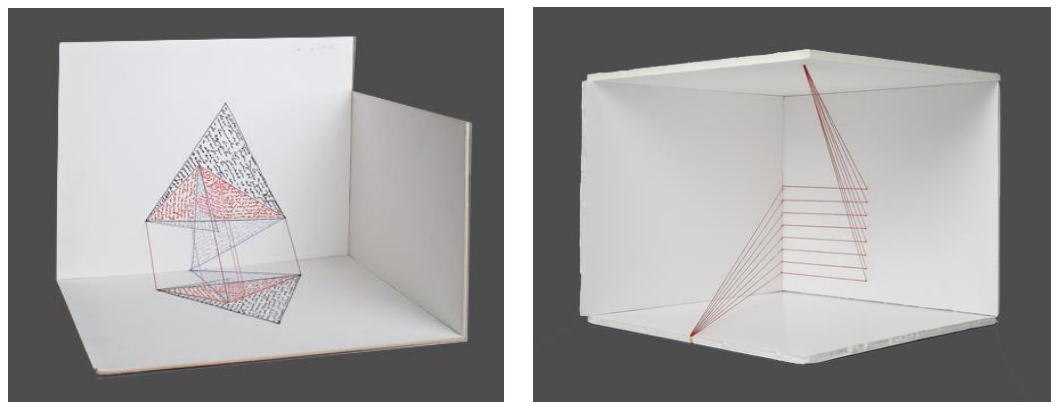

\section{Referencias}

Ferrer, E. (2018). Espacios Entrelazados. "Catalogo de la exposición”. 16 de marzo hasta el 10 de junio de 2018. Museo Guggenheim Bilbao.

Ferrer, E. Todas las variaciones son válidas, incluida esta. "Catalogo de la exposición”. Palacio Velázquez, 26 de octubre de 2017 - 25 de febrero de 2018. Museo Nacional Centro de Arte Reina Sofía. Madrid.

Ibañez, R. (2018) Variaciones artísticas del teorema de Napoleón. En Cuaderno de Cultura Científica. Recuperado de https://culturacientifica.com/2018/01/24/variaciones-artisticas-delteorema-napoleon/

Web personal de Esther Ferrer. http://estherferrer.fr/es/ 
Josu Rekalde-Izagirre: Grupo de Investigación IKERSOINU.

Departamento de Arte y Tecnología. Universidad del País Vasco/Euskal Herriko Unibertsitatea UPV/EHU

Email address: josu.rekalde@ehu.eus

Web: www.josurekalde.com

Contact Address: University of the Basque Country UPV/EHU. 